This is an electronic reprint of the original article. This reprint may differ from the original in pagination and typographic detail.

Author(s): Ryba, Tatiana V.

Title: $\quad$ Cultural Sport Psychology : A Critical Review of Empirical Advances

Year: $\quad 2017$

Version:

Please cite the original version:

Ryba, T. V. (2017). Cultural Sport Psychology : A Critical Review of Empirical Advances. Current Opinion in Psychology, 16, 123-127.

https://doi.org/10.1016/j.copsyc.2017.05.003

All material supplied via JYX is protected by copyright and other intellectual property rights, and duplication or sale of all or part of any of the repository collections is not permitted, except that material may be duplicated by you for your research use or educational purposes in electronic or print form. You must obtain permission for any other use. Electronic or print copies may not be offered, whether for sale or otherwise to anyone who is not an authorised user. 


\section{Accepted Manuscript}

Title: Cultural Sport Psychology: A Critical Review of Empirical Advances $<!-<$ RunningTitle $>$ Cultural Sport Psychology $<$ RunningTitle $>->$

Author: Tatiana V. Ryba

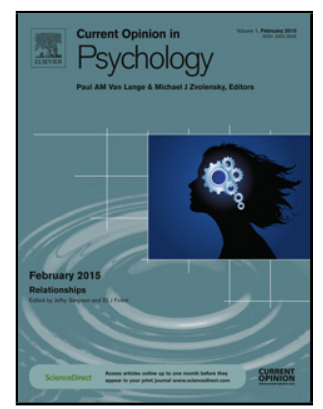

PII:

S2352-250X(16)30172-5

DOI: http://dx.doi.org/doi:10.1016/j.copsyc.2017.05.003

Reference: COPSYC 451

To appear in:

Please cite this article as: Tatiana V.Ryba, Cultural Sport Psychology: A Critical Review of Empirical Advances (2010), http://dx.doi.org/10.1016/j.copsyc.2017.05.003

This is a PDF file of an uncuited manuscript that has been accepted for publication. As a service to our customers we are providing this early version of the manuscript. The manuscript will undergo copyediting, typesetting, and review of the resulting proof before it is published in its final form. Please note that during the production process errors may be discovered which could affect the content, and all legal disclaimers that apply to the journal pertain. 


\title{
Cultural Sport Psychology: A Critical Review of Empirical Advances
}

Tatiana V. Ryba

University of Jyvaskyla

Department of Psychology

P.O. Box 35

FI-40014, Finland

Email: tatiana.ryba@jyu.fi

Mobile: +358408014850

\section{Highlights}

- Sociocultural domain is one of the factors constituting human psychological phenomena

- Cultural transitions and athlete acculturation studies are reviewed

- Empirical literature framed in cultural praxis of athletes' careers is reviewed

- Directions for future work in cultural sport psychology are suggested

\begin{abstract}
Despite a long standing assertion that sociocultural domain is one of the factors constituting human psychological phenomena, sport psychological science has only recently begun to examine culture as the principal basis of physical activity and sport participants' behaviour, wellbeing, engagement, and performance outcomes. Emphasizing the centrality of culture in bringing meaning to athlete careers and life projects, I summarise empirical literature explicitly positioned within cultural sport psychology (CSP). Specifically, I focus on two areas of psychological inquiry - acculturation and athletic career-in which the CSP theoretical tenets and agenda stimulated emergence of novel research trajectories. I conclude by suggesting directions for future work in CSP.
\end{abstract}




\section{Introduction}

Cultural sport psychology (CSP) is a rapidly growing genre of sport psychology that has challenged the normative psychological discourse on viewing psychological processes as autonomous or, at best, interacting with sociocultural environment at the level of individual experience. Scholars within CSP emphasize a constitutive rather than a causal role of cultural and social historicity in people's lives and identities, advocate for opening the privileged intellectual space for marginalised topics and ethics of difference, and facilitate a cultural praxis work of addressing pressing local issues by engaging contemporary theories and research in culturally reflexive ways [1-6]. Recently, CSP scholarship branched out to the empirical arena to expand understandings of the specific ways in which cultural discourses and practices are enmeshed with personal meanings and experiences, resulting in affording, shaping and/or limiting athletic talent, psychological skills and career development [7-10], performance and wellbeing [11-14], subjectification, identity negotiations, and coach-athlete and peer relationships [15-18], as well as physical activity and lifestyle sport participation [19, 20]. Although empirical work is in its infancy, the CSP theoretical tenets and agenda stimulated emergence of novel research trajectories, especially in the study of multiple and overlapping identities and/or subjectivity of athletes, practitioners, and researchers. In 2015-16, a thematic section of the Psychology of Sport and Exercise highlighted articles using critical methodologies to address issues of power and sociocultural difference in athlete formation [21]; and two comprehensive meta-studies of athletic identity research that analysed the stimulating influences of CSP were published $[22,23]$. Therefore, in this review, I focus on two other content areas of sport psychology in which CSP scholars made the most notable impact: (a) cultural transitions and acculturation of athletic migrants; and (b) cultural praxis of athletes' careers. 


\section{Cultural transitions and critical acculturation}

According to the International Organisation for Migration (IOM), 214 million individuals were considered to be migrants in 2013, which is one in every 33 persons worldwide [24]. The historically unprecedented pace of sport globalisation and transnational movement of people for a variety of reasons, such as international assignments and career opportunities, training camps, or fleeing life threatening circumstances, have heightened the need to understand implications of the processes of cultural transition and acculturative change for migrants' health, athletic and psychosocial development, and meaningful life. The most recent systematic work in this area has been approached from two complementary perspectives; that is, the process of cultural transition, or the process undergone by transnational/migrant athletes as they react to and begin to adjust to a new society and new personal circumstances, has been studied from a transnational framework $[10,25-27]$ while acculturation of indigenous and immigrant athletes was examined from a critical epistemological position $[11,28-30]$. Because psychological analyses of transition and acculturation have been dominated by interactionist conceptualisations, in which the individual and environment are treated as independent [43], the CSP influences are evident in how these psychological concepts are being re-articulated as culturally constituted processes that are complex, multifaceted, and dynamically produced within matrices of social power.

The first study to critique a linear model of acculturation in favour of an open-ended, critical conception was an examination of acute cultural adaptation to a training site as experienced by Finnish elite level swimmers in transnational migration [25]. Ryba and her colleagues indicated that cognitive, social, and affective processes were implicated in the swimmers' negotiations of basic psychological needs satisfaction in daily practices and, thus, the manner in which acculturation pathways were generated. The authors introduced a concept of 
discursive cultural space, constructed by physical and discursive practices of the swimming team, which mediated the process of individual adaptation in athletic and non-athletic environments. Importantly, relational contexts, such as those created with coaches and peers at the destination, were suggested to influence differing acculturation trajectories, including their associations with migrant athletes' motivation and psychological wellbeing.

Aligning with a critical view of acculturation as a continuous process, catalyzed with each encounter of unfamiliar cultural practices, several studies by Schinke and his colleagues exemplified diversity of acculturation pathways within various social contexts [11, 28-30]. For example, the studied immigrant athletes and coaches $[11,29,30]$ and aboriginal athletes in a Euro-Canadian $[28,39]$ cultural context reported the need to navigate between cultural norms of the original and destination communities in a continuous process of negotiating meanings and their subject positions. The complexity of acculturation trajectories was forefronted by showing how some migrants confronted racism, exclusion, and damaging stereotypes while simultaneously feeling disconnected from their ethnic communities as well as experienced marginalisation, identity crisis, and acculturative stress upon their return to the origin. A major contribution from this line of research includes positioning migrant athletes' acculturation as adaptive or maladaptive dependent on whether it is construed as shared with peer athletes and the coaches from the receiving country (i.e., two-way) or shouldered (one-way) effort of the migrant athlete to adapt to new surroundings with no adjustment from the hosts.

An innovative approach to study acculturative change in time-based trajectories was taken in a recent analysis of transnational athletes' life stories with an aim to deepen current understandings of the processes activated in cultural transition [27]. Having positioned the migrants' experiences in critical acculturation literature, Ryba and colleagues proposed a 
temporal model of the cultural transition process consisting of three phases: pre-transition, acute acculturation, and sociocultural adaptation. The two latter phases occur post relocation from the origin and each transitional phase presents developmental tasks that shape acculturation pathways. The authors emphasised that although psychological processes are time dependent, subjective time is non-linear and intertwined with the patterns of migration. For example, transnational athletes who periodically travel to and from their country of origin may undergo cyclical acculturation that is likely to be qualitatively different from the acculturation process of 'sedentary' migrants or 1.5 generation immigrants. Based on the extensive data of transnational athletes' experiences, Ryba et al. suggested that cultural transition is animated by the following adaptive mechanisms: (a) repositioning and calibration of social relations and networks, (b) negotiation of cultural practices, and (c) decoding and reconstruction of meanings that regulate individual functioning in a specific environment.

To summarise, the study of athletic migrants' acculturation from a critical or transnational framework is the newly developing discourse in sport psychology, in which acculturation is viewed as constructed across a broad range of social, cultural, and political contexts in the cultural transition process. The reviewed studies exemplify that acculturative changes occur in all aspects of daily life, such as sport, school, relationships, and may not follow the same trajectory in relation to, for example, time or dimensions of cultural identifications. From a critical psychological perspective, acculturation is open-ended and ongoing, executed in cognitive movements between different cultural standpoints, and consequently difficult to predict and regulate. While change and flux constitute acculturation processes, the work of cultural transition is a psychological work of repairing the rupture of one's subjectified world to enable individual functioning within new cultural patterns of meaning. The process of cultural transition 
reaches its symbolic end when a transnational migrant establishes the meaningful relationship between self and society at the destination, manifested in optimal psychological functioning. The reviewed studies moreover highlighted the urgency to understand constitutive effects of receiving contexts on the processes of acculturation, and their associations with athletic migrants' health, performance, and psychosocial development, thus serving as catalysts of emergent research inquiries into the perspectives of receiving communities $[31,45]$.

\section{Cultural praxis of athletes' careers}

Cultural praxis of athletes' careers, proposed by Stambulova and Ryba [32, 33], is a culturally centered perspective on the life designing processes in and through sport that interlocks career theories, research, and assistance with athletes' developmental environments in cultural praxis. The heuristic builds upon a holistic athletic career model [34] and a holistic ecological approach in talent/career development [35] in combination with some aspects of the athletic career transition model [36], and links these with cultural praxis tenets [37, 2-5] to form a contextually engaging academic discourse. To move beyond theoretical discussions of cultural praxis in CSP, Stambulova and Ryba articulated a set of challenges for career researchers and practitioners, which include: (a) reflexive positioning of career projects in particular sociocultural contexts, (b) taking a holistic perspective on athletic career as being a part of the life design, (c) applying critical and culturally sensitive methodologies to discern meanings underpinning career behaviour, and (d) an increasing attention to diversity of career patterns and their construction in a mobile transnational world.

During 2015-16, seven studies were published that attempted to meet some of the aforementioned challenges. Three studies that were explicitly positioned within cultural praxis of athletes' careers, focused on examining dual career transitions of Swedish [38], Canadian 
Aboriginal [39], and transnational [10] athletes. In addition to applying a holistic developmental perspective to account for athletes' simultaneous transitions in sport (e.g., from junior to senior level) and education (e.g., to higher education), as well as changes in their social networks (e.g., teammates and coaches), these studies made the case of centralising sociocultural influences in achieving a rich understanding of the athletes' experience of dual career transitions.

In a study of Swedish youth athletes' transition and adaptation to elite sport schools during their first year, Stambulova and her colleagues [38] adopted a longitudinal mixed methods design that allowed the authors to derive an empirically grounded conceptualisation of the optimal dual career balance. Following the youth athletes' reflections on their inability to give $100 \%$ to all aspects of their daily living, Stambulova et al. formulated a recommendation for service providers to support athletes in making their dual career efforts complementary rather than comparable. The authors also developed the Swedish dual career model aligned with the national educational/vocational and sport systems. In their studies with indigenous and transnational athlete migrants who relocated to advance their careers and life opportunities, Blodgett and Schinke [39], and Ryba et al. [10], respectively, revealed that cultural transitions intersected with and shaped the transitioning athletes' experiences that subsequently animated their dual career decisions and life choices. The use of critical qualitative methodologies to elicit participants' stories and unique meanings resulted in a powerful and culturally resonant mode of knowledge production. As concluded by the above listed authors, young peoples' meanings assigned to their life projects provide distinct insights into trajectories of dual career development; and structural and discursive conditions in specific localities (e.g., economic crisis, lack of coaching expertise) impact and mediate athletes' agency with respect to career decisions and behaviours (e.g., relocate due to global events, retire prematurely). Moreover, acknowledging the growing 
numbers of athletes "on the move," sport psychology professionals are called upon to become culturally competent and consider cultural transitions as the basis for formulating a better understanding of athletes' experiences and decision-making in a transnational context [45].

A common thread among the other four studies $[40-42,15]$ is that they examined sporting narratives and gendered cultural practices that create a discursive field of athletic career from which athletes derive meanings underpinning their career construction. In a study of preretirement experiences among Finnish elite level runners, Ronkainen and her colleagues [40] found that the participants' gender was actively lived and felt through the meanings assigned to their life projects, expressed in differing decision-making and retirement patterns. In a similar vein, Ryba et al. [41] analysed gendered career accounts that were linked to various discourse practices, such as those of the exemplary career and a good life, which "dictate us to think of careers in certain way." These career discourses exist alongside each other within an interconnected transnational space of elite sport and are uniquely reinterpreted in specific cultural localities. The authors distinguished between an objective athletic career that implies a stage-based, progressive development, and a subjective career embedded in a more comprehensive and fluid discourse about life opportunities. Advancing this work, Ronkainen and Ryba [42] critically analysed dominant theoretical understandings of athletic career and career termination from an existential-narrative lens. The authors argued that the prevalent career models in sport psychology are framed in western cultural narratives of ageing as decline and disregard athletes' agency in constructing subjective careers. In an effort to contribute to the growth of cultural praxis of athletes' careers, Ronkainen and Ryba pushed the boundaries of the emergent discourse towards phenomenological body and existential themes of ageing, authenticity and finitude. The study by Kavoura and colleagues [15] employed discourse analysis 
to trace the discourses through which Greek female judokas make sense of their career experiences and themselves. The findings revealed that oppressive gender discourses not only shaped female athletes' experiences, but had also infiltrated their subjectivities in as much that they became implicated in reproducing gender hierarchy in martial arts.

The reviewed studies provide a compelling representation of the reciprocal influences between athletes' individual development and the environment in which they are embedded, encompassing diverse discursive-narrative fields competing for athletes' subjectivities. Within the cultural praxis of athletes' careers framework, athletic career acquires experience and importance through a series of specific practices that impact the way individuals behave, identify themselves, as well as reproduce cultural meanings and symbolic order.

\section{Directions for future research}

The present review summarised recent critical acculturation and athlete career transitions literature that empirically advanced the CSP rationale. My suggestions for future directions in CSP stem from its three-pronged tenets aimed at: (a) furthering a constitutive rather than a causal role of cultural and social historicity in people's lives and identities; (b) advocating for ethics of difference; and (c) facilitating cultural praxis work.

First, much of the available research that has focused on producing a multidimensional and rich representation of the cultural constitution of psychological phenomena is cross-sectional. Taking into consideration that the relationship between psychological and sociocultural processes are formed over time, creating continuity and change across differing contexts and environments, it will be useful to employ longitudinal research designs to demonstrate how these processes are mutually constituting. It is critical, moreover, to maintain ontological commitment to mapping out constitutive relations without slipping into a linear view of causality whereby 
allowing the longitudinal method to determine the way in which person-environment relations is conceptualised. See excellent articles by Heft [43] for the discussion of causal vs. constitutive relations between culture and psychological processes, and McGannon and Smith [4] for the overview of narrative and discursive methodologies in CSP research.

Second, a majority of CSP research has been conducted within the privileged space of whiteness. It will be important to expand this research to other geopolitical regions and cultural value systems. What are the values of physical activity and sport in different regions? How do these values permeate and shape performative identity, interpersonal relationships, and the ways in which people relate to the in-group and out-group individuals? How is difference negotiated and socialised in sporting cultural spaces? Answering these questions is necessary for advancing empirical CSP to create inclusive spaces and informing culturally competent and ethical service provision in an increasingly diversified world. Furthermore, ethical considerations are inherent in comparative cultural research and applied work in multicultural environments, and should be taken seriously to promote addressing cultural difference as contextually situated, relational, and fluid (see also Ryba et al. [2] and Schinke et al. [44]).

Third, the pace of sport globalisation and transnational movement of peoples, ideas, and cultural practices in the last 20 years has accelerated for some sport participants and professionals faster than they can adapt. How can healthy communities be built that are flexible and mobile to draw energy from acceleration of space and time, and simultaneously sustainable to provide dynamic stability and sense of belonging to their members? The challenge of engendering cultural praxis in hybrid environments will be warranted for the vitality of CSP projects in the future that is unfolding now. 


\section{References and recommended reading}

Papers of particular interest published within the period of 2010-2016 have been highlighted as:

* of special interest

** of outstanding interest

**1. Ryba, T. V., Schinke, R. J., \& Tenenbaum, G. (2010). (Eds.) The cultural turn in sport psychology. Morgantown, WV: Fitness Information Technology.

2. Ryba, T. V., Stambulova, N., Si, G., \& Schinke, R. (2013). The ISSP position stand: Culturally competent research and practice in sport and exercise psychology. International Journal of Sport and Exercise Psychology, 11, 123-142. http://dx.doi.org/10.1080/1612197X.2013.779812

3. Blodgett, A. T., Schinke, R. J., McGannon, K. R., \& Fisher, L. A. (2014). Cultural sport psychology research: Conceptions, evolutions, and forecasts. International Review of Sport and Exercise Psychology, 8, 24-43. doi:10.1080/1750984X.2014.942345

4. McGannon, K. R., \& Smith, B. (2015). Centralizing culture in cultural sport psychology research: The potential of narrative inquiry and discursive psychology. Psychology of Sport and Exercise, 17, 79-87. doi:10.1016/j.psychsport.2014.07.010

5. Schinke, R. J., McGannon, K., Parham, W., \& Lane, A. (2012). Toward cultural praxis and cultural sensitivity: Strategies for self-reflexive sport psychology practice. Quest, 64, 3446. doi:10.1080/00336297.2012.653264

6. Sarkar, M., Hill, D., \& Parker, A. (2014). Working with religious and spiritual athletes: Ethical considerations for sport psychologists. Psychology of Sport and Exercise, 15(6), 580-587. DOI: 10.1016/j.psychsport.2014.05.006

7. Henriksen, K., Larsen, C. H., \& Christensen, M. K. (2014). Looking at success from its opposite pole: The case of a talent development golf environment in Denmark, 
International Journal of Sport and Exercise Psychology, 12, 134-149, DOI:

10.1080/1612197X.2013.853473

8. Coulter, T., Mallett, C.J., \& Singer, J.A. (2016). A subculture of mental toughness in an Australian Football League club. Psychology of Sport and Exercise, 22, 98-113. doi:10.1016/j.psychosport.2015.06.007

9. Storm, L.K., Henriksen, K., \& Christensen, M.K. (2012). Specialization pathways among elite Danish athletes: A look at the developmental model of sport participation from a cultural perspective. International Journal of Sport Psychology, 43, 199-222.

10. Ryba, T. V., Stambulova, N. B., Ronkainen, N. J., Bundgaard, J., \& Salänne, H. (2015). Dual career pathways of transnational athletes. Psychology of Sport and Exercise, 21, 125-134. doi:10.1016/j.psychosport.2014.06.002

11. Schinke, R. J., McGannon, K. R., Battochio, R. C., \& Wells G. (2013). Acculturation in elite sport: A thematic analysis of immigrant athletes and coaches. Journal of Sport Sciences, 31, 1676-1686. doi:10.1080/02640414.2013.794949

12. Richardson, D., Littlewood, M., Nesti, M., \& Benstead, L. (2012) An examination of the migratory transition of elite young European soccer players to the English Premier League. Journal of Sports Sciences, 30, 1605-1618, DOI:10.1080/02640414.2012.733017

13. Tibbert, S., Andersen, M., \& Morris, T. (2015). What a difference a "Mentally Toughening" year makes: The acculturation of a rookie. Psychology of Sport and Exercise, 17, 68-78. doi:10.1016/j.psychosport.2014.10.007

14. Busanich, R., McGannon, K.R., \& Schinke, R.J. (2016). Exploring disordered eating and embodiment in male distance runners through visual narrative methods Qualitative Research in Sport, Exercise and Health, 8, 95-112. 
https://doi.org/10.1080/2159676x.2015.1028093

15. Kavoura, A., Ryba, T. V., \& Chroni, S. (2015). Negotiating female judoka identities in Greece: A Foucauldian discourse analysis. Psychology of Sport and Exercise, 17, 88-98. http://dx.doi.org/10.1016/j.psychsport.2014.09.011

16. Carless, D., \& Douglas, K. (2013). Living, resisting, and playing the part of athlete: Narrative tensions in elite sport. Psychology of Sport and Exercise, 14 (5), 701-708. DOI: 10.1016/j.psychsport.2013.05.003

17. McGannon, K., Gonsalves, C., Schinke, R., \& Busanich, R. (2015). Negotiating motherhood and athletic identity: A qualitative analysis of Olympic athlete mother representations in media narratives. Psychology of Sport and Exercise, 20, 51-59.

DOI: 10.1016/j.psychsport.2015.04.010

18. Khomutova, A. (2015). Basketball coaches' experience in working with multicultural teams: Central and northern European perspectives. Sport in Society, 19, 861-875. doi:10.1080/17430437.2015.1067777

*19. McGannon, K.R., \& Schinke, R.J. (2013) "My first choice is to work out at work; then i don't feel bad about my kids": A discursive psychological analysis of motherhood and physical activity participation Psychology of Sport and Exercise, 14, 179-188. doi:10.1016/j.psychsport.2012.10.001

20. Ronkainen, N., Ryba, T. V., \& Nesti, M. (2013). 'The engine just started coughing!' - Limits of physical performance, aging and career continuity in elite endurance sports. Journal of Aging Studies, 27(4), 387-397. DOI: http://dx.doi.org/10.1016/j.jaging.2013.09.001

21. Schinke, R.J., \& McGannon, K.R. (2015). Cultural sport psychology and intersecting identities: an introduction to the special section. Psychology of Sport and Exercise, 17, 
45-47. http://dx.doi.org/10.1016/j.psychsport.2014.10.010

22. Ronkainen, N. J., Kavoura, A., \& Ryba, T. V. (2016). A meta-study of athletic identity research in sport psychology: Current status and future directions. International Review of Sport and Exercise Psychology, 9(1), 45-64. http://dx.doi.org/10.1080/1750984X.2015.1096414.

*23. Ronkainen, N. J., Kavoura, A., \& Ryba, T. V. (2016). Narrative and discursive perspectives on athletic identity: Past, present, and future. Psychology of Sport and Exercise, 7, 128137. http://dx.doi.org/10.1016/j.psychsport.2016.08.010

24. International Organization for Migration. (2013). Facts and figures. Retrieved November 15, 2016, from http://www.iom.int/infographics/migration-facts-and-figures

25. Ryba, T. V., Haapanen, S., Mosek, S., \& Ng, K. (2012). Towards a conceptual understanding of acute cultural adaptation: A preliminary examination of ACA in female swimmers. Qualitative Research in Sport, Exercise and Health, 4, 80-97. doi:10.1080/2159676X.2011.653498.

26. Agergaard, S., \& Ryba, T. V. (2014). Migration and career transitions in professional sports: Transnational athletic careers in a psychological and sociological perspective. Sociology of Sport Journal, 32(2), 228-247. DOI: http://dx.doi.org/10.1123/ssj.2013-0031

*27. Ryba, T. V., Stambulova, N. B., \& Ronkainen, N. J. (2016). The work of cultural transition: An emerging model. Frontiers in Psychology, 7, 427. doi.org/10.3389/fpsyg.2016.00427

*28. Blodgett, A. T., Schinke, R. J., Coholic, D. A., Enosse, L., Peltier, D., Pheasant, C. (2014). Navigating the insider-outsider hyphen: A qualitative exploration of the acculturation challenges of Aboriginal athletes pursuing sport in Euro-Canadian contexts. Psychology of Sport and Exercise, 15, 345-355. doi:10.1016/j.psychsport.2014.02.009 
*29. Schinke, R. J., Blodgett, A. T., McGannon, K. R., \& Ge, Y. (2016). Finding one's footing on foreign soil: A composite vignette of elite athlete acculturation. Psychology of Sport and Exercise. 25, 36-43. doi:10.1016/j.psychsport.2016.04.001.

30. Schinke, R. J., Blodgett, A. T., McGannon, K. R., Ge, Y., Oghene, O., \& Seanor, M. (2016). Adjusting to the receiving country outside of the sport environment: A composite vignette of Canadian immigrant amateur elite athlete acculturation. Journal of Applied Sport Psychology. Advance online publication. doi:10.1080/10413200.1243593

31. Elbe, M. A., Hatzigeorgiadis, A., Morela, E., Ries, F., Kouli, O., \& Sanchez, X. (2016). Acculturation through sport: Different contexts different meanings. International Journal of Sport and Exercise Psychology. Advance online publication. doi:10.1080/16122197.2016.1187654

**32. Stambulova, N. B., \& Ryba, T. V. (2013). (Eds.). Athletes' careers across cultures. London: Routledge. ISBN: 978-0-415-50530-7

33. Stambulova, N. B., \& Ryba, T. V. (2014). A critical review of career research and assistance through the cultural lens: Towards cultural praxis of athletes' careers. International Review of Sport and Exercise Psychology, 7(1), 1-17. DOI:

10.1080/1750984X.2013.851727

34. Wylleman, P., Reints, A., \& De Knop, P. (2013). A developmental and holist ic perspective on athletic career development. In P. Sotiaradou and V. De Bosscher (Eds.), Managing high performance sport (pp.159-182). New York, NY: Routledge.

35. Henriksen, K., Stambulova, N., \& Roessler, K. K. (2010). Holistic approach to athletic talent development environments: A successful sailing milieu. Psychology of Sport and Exercise, 11, 212-222. doi:10.1016/j.psychsport.2009.10.005 
36. Stambulova, N. (2003). Symptoms of a crisis-transition: A grounded theory study. In N. Hassmén (Ed.), SIPF Yearbook 2003 (pp. 97-109). Örebro, Sweden: Örebro University Press.

37. Ryba, T. V., \& Wright, H. K. (2010). Sport psychology and the cultural turn: Notes toward cultural praxis. In T. V. Ryba, R. J. Schinke, \& G. Tenenbaum (Eds.), The cultural turn in sport psychology (pp. 1-28). Morgantown, WV: Fitness Information Technology.

38. Stambulova, N. B., Engström, C., Franck, A., Linnér, L., \& Lindahl, K. (2015). Searching for an optimal balance: Dual career experiences of Swedish adolescent athletes. Psychology of Sport and Exercise, 21, 4-14.

39. Blodgett, A. T., \& Schinke, R. J. (2015). "When you're coming from the reserve you're not supposed to make it”: Stories of Aboriginal athletes pursuing sport and academic careers in "mainstream" cultural contexts. Psychology of Sport and Exercise, 21, 115-124. doi:10.1016/j.psychsport.2015.03.001

40. Ronkainen, N. J., Watkins, I., \& Ryba, T. V. (2016). What can gender tell us about the preretirement experiences of elite distance runners in Finland?: A thematic narrative analysis. Psychology of Sport and Exercise, 22, 37-45. doi:10.1016/j.psychsport.2015.06.003

41. Ryba, T. V., Ronkainen, N. J., \& Selänne, H. (2015). Elite athletic career as a context for life design. Journal of Vocational Behavior, 88, 47-55. DOI: 10.1016/j.jvb.2015.02.002

42. Ronkainen, N. J., \& Ryba, T. V. (2017). Rethinking age in athletic retirement: An existentialnarrative perspective. International Journal of Sport and Exercise Psychology, 15(2), 146-159. http://dx.doi.org/10.1080/1612197X.2015.1079920 
43. Heft, H. (2013). Environment, cognition, and culture: Reconsidering the cognitive map. Journal of Environmental Psychology, 33, 14-25.

44. Schinke, R. J., Papaioannou, A. G., \& Schack, T. (2016). (Eds.). Sport psychology in emerging countries. International Journal of Sport and Exercise Psychology, 14(2).

45. Ryba, T. V., Schinke, R. J., Stambulova, N., \& Elbe, A-M. (2017). ISSP Position Stand:

Transnationalism, mobility, and acculturation in and through sport. International Journal of Sport \& Exercise Psychology. http://dx.doi.org/10.1080/1612197X.2017.1280836 